\title{
Free Hand One Stage Correction of Kyphoscoliosis
}

\author{
Mostafa Aboelkhir \\ Neurosurgery Department, Faculty of Medicine, Al-Azhar University, Cairo, Egypt \\ Email: mostafaaboelkhir81@gmail.com
}

How to cite this paper: Aboelkhir, M. (2022) Free Hand One Stage Correction of Kyphoscoliosis. Open Journal of Modern Neurosurgery, 12, 47-59. https://doi.org/10.4236/ojmn.2022.121005

Received: November 4, 2021

Accepted: January 24, 2022

Published: January 27, 2022

Copyright (c) 2022 by author(s) and Scientific Research Publishing Inc. This work is licensed under the Creative Commons Attribution International License (CC BY 4.0).

http://creativecommons.org/licenses/by/4.0/

(c) (i) Open Access

\begin{abstract}
Background: Scoliosis is a complex musculoskeletal torsional deformity of spine that includes: Lateral curvature in the anterior-posterior plane with a Cobb angle greater than 10 degrees, Angulation in the sagittal plane, or Rotation in the transverse plane. Scoliosis classified into neuromuscular, idiopathic, or congenital. Radiological evaluation is done by plain radiography, computed tomography (CT), and magnetic resonance (MR). We aimed to evaluate patients with idiopathic kyphoscoliosis who underwent a freehand posterior approach for scoliosis correction through transpedicular screws fixation. Setting: Al-Azhar University Hospitals. Subjects and Methods: Study was performed on 12 patients with idiopathic kyphoscoliosis who underwent a freehand posterior approach for scoliosis correction through transpedicular screws fixation in Al-Azhar University Hospitals between 2015 to 2018 \& follow up for one year. Results: Early outcome showed improved Cobb's angle and coronal balance significantly after surgery. Correction is $95 \%$ in 2 cases (17\%), $80 \%$ correction in 8 cases (66\%), $60 \%$ correction in 2 cases (17\%). 2 cases have CSF leakage which improved with conservative treatment. Late follow-up shows improvement of patient deformity and cosmetic appearance to the degree of patient satisfaction occur in 7 cases (58\%) associated with high SRS-30 total scores. However, assessment of the pain in comparison to preoperative assessment show improvement of pain in 4 cases (33\%), persistent in 4 cases (33\%), appear in 4 cases (33\%). Conclusion: Freehand onestage correction management of idiopathic kyphoscoliosis through the posterior approach is a safe and effective for near-total correction of deformity with a good outcome with minimal complications.
\end{abstract}

\section{Keywords}

Free Hand One Stage Correction, Kyphoscoliosis

\section{Introduction}

Scoliosis is a complex musculoskeletal three-dimensional torsional deformity of 
the spine that includes [1]: -

a) Lateral curvature in the anterior-posterior plane with a Cobb angle measuring greater than 10 degrees,

b) Angulation in the sagittal plane,

c) Rotation in the transverse plane [1].

Scoliosis Classification (Figure 1):

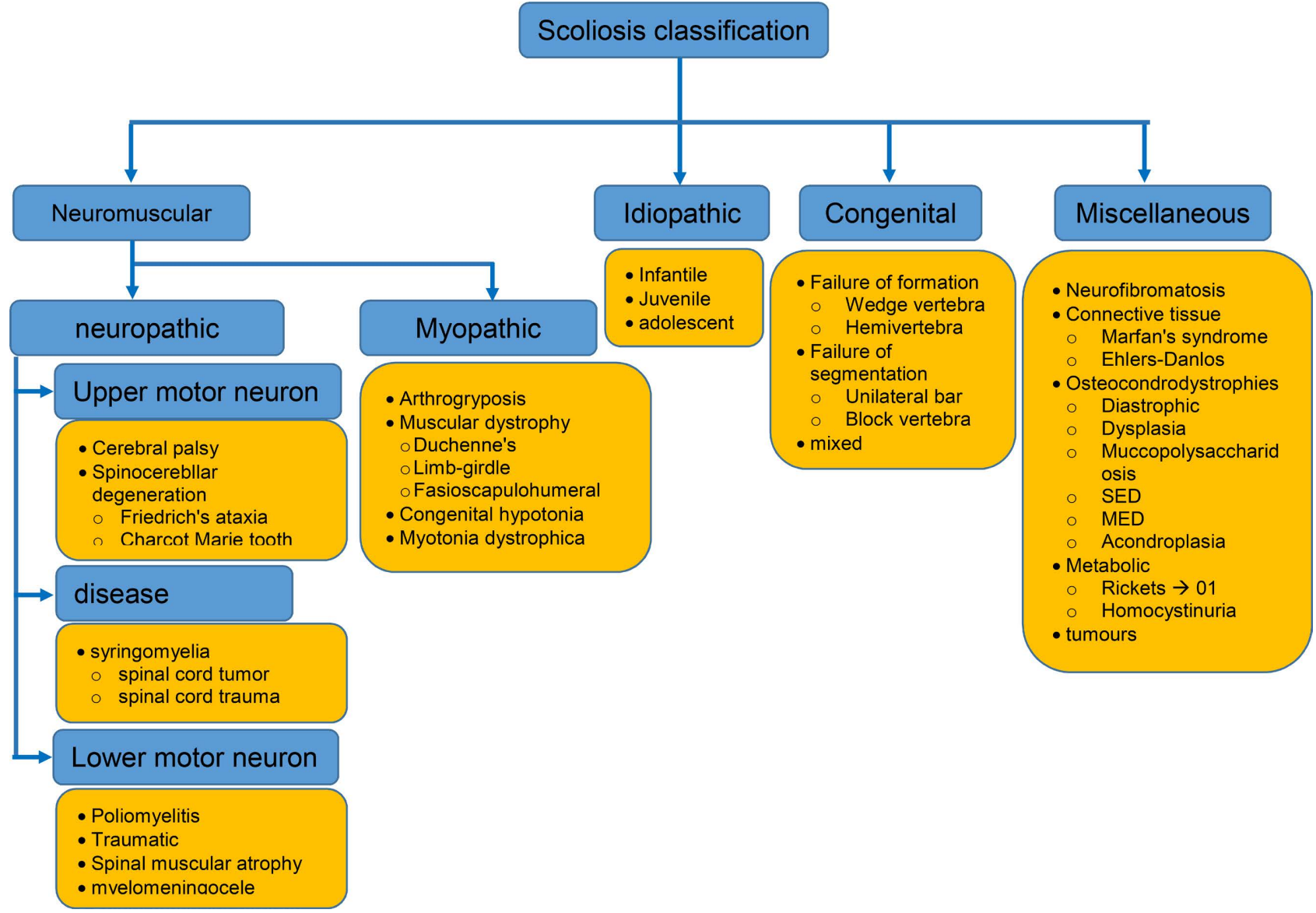

Figure 1. Scoliosis Classification [2].

1) Congenital scoliosis (Figure 2).
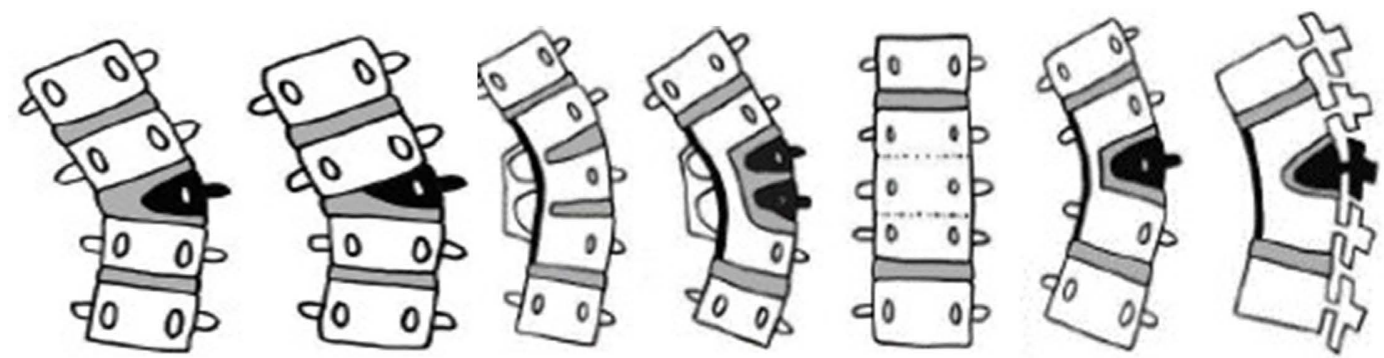

Figure 2. Ccongenital scoliosis [3].

2) Neuromuscular Scoliosis [4]: This is arising as a result of neurologic or muscular disorders. 
a) Neuropathic causes include

- Upper Motor Neuron Lesions, such as cerebral palsy, spinocerebellar degeneration, syringomyelia, spinal cord tumors, and trauma [5].

- Lower Motor Neuron Lesions, such as poliomyelitis, spinal muscular atrophy, and myelomeningocele [6].

b) Myopathic Conditions include muscular dystrophies [7].

3) Idiopathic Scoliosis [8]:

- Idiopathic Scoliosis is a diagnosis of exclusion, so neurological causes for the deformity must be ruled out by medical history, clinical examination, radiographs, and in selected cases by axial imaging [9]. It is the most common type which accounts for up to $80 \%$ of scoliosis in children [10].

- It is classified based on the age of onset into; -

i) Infantile ( 0 - 3 years), accounts for less than $1 \%$, common in boys, convex left curves.

ii) Juvenile (3 - 10 years), makes up between $12 \%$ and $21 \%$

iii) Adolescence (>10 years), the most common is about $90 \%$ of cases [11].

- These 3 periods mark the different periods of growth velocity during childhood; hence, the curves behave differently [12].

- More recently childhood scoliosis is divided into two categories; early-onset, ( $<5$ years), late-onset ( $>5$ years) [13].

This may be a more appropriate division as:

i) Growth velocity of the spine peaks between birth and the age of five,

ii) Treatment methods for patients with scoliosis when younger than 5 years is significantly different from patients presenting with scoliosis when older than 5 years,

iii) Periods of pulmonary development; from 0 to 5 years of age is the period of major pulmonary development, so cardiopulmonary complications are more likely seen when onset occurs before the age of five [14].

\section{Curves are at risk for progression}

1) During periods of rapid skeletal growth, specifically the first 2 years of life and the adolescent growth spurt.

2) Large curves.

3) Skeletally immature patients especially with curves greater than 20.

4) Thoracic and double curve patterns are at higher risk of progression than thoracolumbar curves.

5) Curve Degree, Curves less than 30 degrees at skeletal maturity are thought to be mostly stable and unlikely to progress over time. Curves greater than 50 degrees at skeletal maturity commonly progress at a rate of up to 1 degree per year for thoracic curves. Curves between 35 and 50 degrees at skeletal maturity present a diagnostic dilemma due to insufficient clinical data and should be followed radiographically into adulthood [15].

\section{Radiological Evaluation}

- Imaging modalities such as plain radiography, computed tomography (CT), 
and magnetic resonance (MR) imaging play vital roles in the diagnosis of scoliosis,

- In interpreting the imaging features of scoliosis, it is essential to identify the significance of vertebrae in or near the curved segment, the curve type, the degree of angulation, the degree of vertebral rotation, and the longitudinal extent of spinal involvement [16].

- Plain films (Figure 3) to assess and document the actual bony anatomy. The following views are requested: -

i) Posteroanterior (PA) (standing, erect sitting, or supine).

ii) Lateral: The PA and lateral radiographs should include the whole spine, shoulders, and pelvis to allow assessment of the patient's overall skeletal balance as well as skeletal maturity. The curves are described by the direction of the convexity and the location of the apex.

iii) Side-bending films or lateral-bending films assess the flexibility of the curve [17] [18].

- If a neuraxial cause is being sought, magnetic resonance (MR) imaging of the entire brain and spinal cord is indicated, MR imaging helps assess the craniocervical junction, any split cord malformations, and tethering of the cord. There is an increasing trend to obtain an MRI scan for any patient requiring operative treatment of their scoliosis to rule out any unexpected intraspinal abnormality [19]. So, MRI is indicated for

o All patients presenting with early-onset scoliosis [20].

o For Patients with Abnormal Neurologic Examination [20].

o It is not routinely performed for patients with AIS, except for those with Pain, Atypical Curve patterns Large Curves on Presentation, or Rapidly Progressive curves [21].
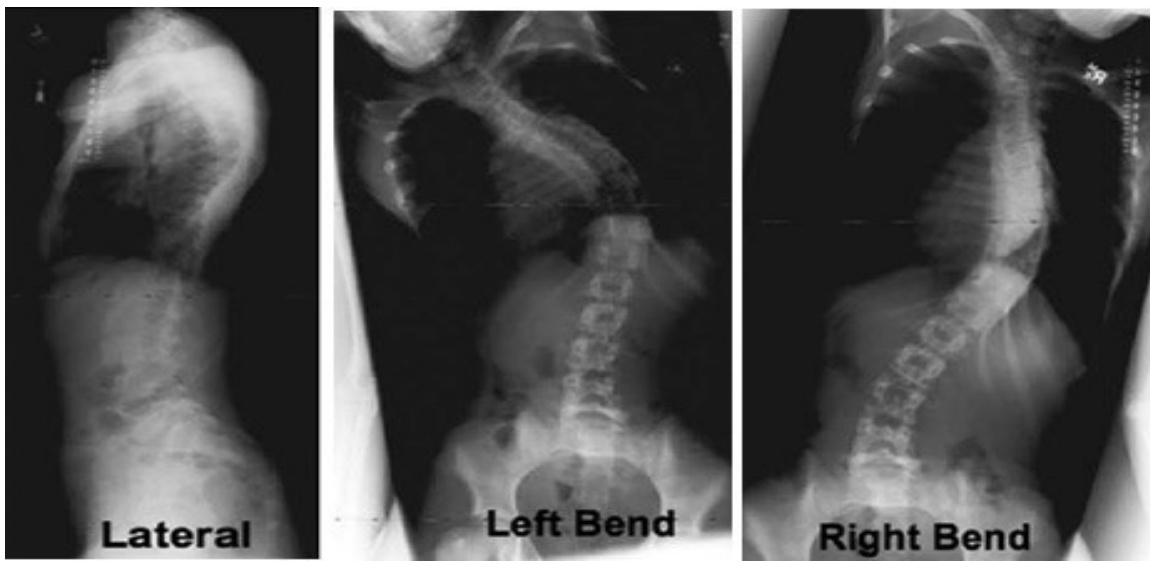

Figure 3. Plain radiograph films of a patient with scoliosis in different views [22].

\section{Treatment}

- Early-onset idiopathic scoliosis is treated to prevent future cardiopulmonary problems, whereas treatment for late-onset idiopathic scoliosis is done to ease deformity and improve the appearance, and to prevent significant psychoso- 
cial distress [23].

- Early-onset idiopathic scoliosis is the only type of scoliosis that benefit from nonoperative treatment

- Because the natural history of AIS at skeletal maturity is the continued progression of the curve into adulthood only if the deformity is greater than 50, the ultimate goal of the treatment of AIS is to keep scoliosis less than 50 at maturity [21].

- The treatment choices are based on several factors, including curve magnitude, type and location of the curve, level of maturity, remaining growth, cosmetic appearance, and patient psychosocial factors [11].

Treatment for scoliosis: includes

1) Observation [24].

2) Bracing or casting [25]: Bracing is typically indicated in: -

Growing children (skeletally immature patients, Risser 0 or 1,2) and in females who are less than 12 months past menarche) with Progressive curves (Curves that progress by 5 to 10 degrees at 6 -month interval) measuring 20 to 45 degrees,

The goal of bracing is to prevent curve progression and to keep it below the surgical range at skeletal maturity [26].

Bracing and surgery are the mainstays for the treatment of scoliosis [27].

3) Surgery

> The goal of surgical treatment is to arrest the curve progression while improving spinal balance and alignment [28].

Surgery (Fusion with instrumentation) is indicated for:

- Curves 45 degrees in growing children,

- For curves 50 degrees at maturity, and

- For those curves that continue to progress after the cessation of brace treatment [28] [29].

Surgical options include either: -

- Anterior Release or

- Posterior Fusion to improve correction and prevent subsequent rotational and coronal deformity [30].

\section{Patients and Methods}

Aim of the study: This study was conducted to evaluate patients with idiopathic kyphoscoliosis who underwent a freehand posterior approach for scoliosis correction through transpedicular screws fixation.

\subsection{Patients}

This study was performed on 12 patients with idiopathic kyphoscoliosis who underwent a freehand posterior approach for scoliosis correction through transpedicular screws fixation in AL Hussein and Bab Ashaarya Al Azhar University Hospitals between 2015 to 2018 . 


\section{Setting:}

- In Al-Hussein and Bab-Ashaarya Al-Azhar University Hospitals.

Target population:

- Kyphoscoliosis patients

Inclusion criterion:

- All Cases with Idiopathic Kyphoscoliosis with Cobb Angle More than 45 Degrees.

\section{Exclusion criteria:}

- Congenital and Neuromuscular Scoliosis

- Chronic debilitating diseses.

- Traumatic kyphoscoliosis.

\subsection{Methods}

\section{Patients were subjected to the following:}

Preoperative Assessment Preoperative planning to

$\square$ Determine surgical indication and surgical goals through assessment of the patient complaint and cobb angle, skeletal maturity.

$\square$ Determine the level of fixation and diameter of screws needed through study with side bending film and 3D CT in some cases.

\section{Surgical Procedures}

$\square$ Under general anesthesia in the prone position.

$\square$ After muscle separation, facetectomy at scoliotic curve level was done followed by freehand screws insertion.

$\square$ Correction of the curve after rods insertion through one or more of the following;

a) Distraction on the concave side and compression on the convex side.

b) Simple Rod rotation

c) Simultaneous double rod rotation (SDRR)

d) Rod Translation

e) Direct vertebral rotation

f) Use of reduction screws in vertebrae at the concave side of the apex and osteotomy at apical vertebra in high curves

\section{Follow up}

$\square$ Early: For the Following;

a) Degree Of Correction

b) Presence Of Complication and Its Proper management

$\square$ Late: For at least one year to assess: -

a) Functional Out Come with scoliosis research society-30 questionnaire (SRS-30).

b) Radiographic Assessment for Cobbs Angle and patient satisfaction.

\section{Ethical Considerations:}

- All patients will be included in this study only after taking informed consent.

\section{Statistical analysis.}

Data entry and statistical analysis were carried out using MedCalc ver. 18.11.3 
(MedCalc, Belgium).

\section{Results}

Of the 12 patients with idiopathic kyphoscoliosis who underwent freehand surgical correction:

- 9 patients were female, 3 were male.

- Mean age 15 years ranged from (7 - 23).

- 8 cases with a thoracolumbar curve, 4 cases with the thoracic curve.

- 9 cases presented with deformity and back and 3 cases with deformity alone (Table 1).

\section{Outcome}

\section{Early follow up}

Cobb's angle and coronal balance improved significantly after surgery 95\% correction in 2 cases (17\%), 80\% correction in 8 cases (66\%), 60\% correction in 2 cases (17\%).

2 cases have CSF leakage which improved with conservative treatment.

1 case has mal directed screw into disc space, and 1 case has a medial screw into the spinal canal without neurological deficit and no additional procedures was needed.

Late follow up: every 3 months for at least 12 months:

- Improvement of patient deformity and cosmetic appearance to the degree of patient satisfaction occur in 7 cases (58\%) associated with high SRS-30 total scores.

- However, assessment of the pain in comparison to preoperative assessment show improvement of pain in 4 cases (33\%), persistent in 4 cases (33\%), appear in 4 cases (33\%).

Table 1. Patients Demographic and Surgical Criteria.

\begin{tabular}{ccccccc}
\hline Case & Sex & Age & $\begin{array}{c}\text { Cobb angle } \\
(1)\end{array}$ & $\begin{array}{c}\text { Cobb angle } \\
(2)\end{array}$ & $\begin{array}{c}\text { Fusion } \\
\text { levels }\end{array}$ & Follow up \\
\hline 1 & F & $7 \mathrm{Y}$ & 55 & 17 & T4-L2 & $24 \mathrm{~m}$ \\
2 & F & $21 \mathrm{Y}$ & 62 & 12 & T3-T12 & $18 \mathrm{~m}$ \\
3 & M & $16 \mathrm{Y}$ & 51 & 15 & T2-L2 & $18 \mathrm{~m}$ \\
4 & F & $22 \mathrm{Y}$ & 70 & 16 & T5-L3 & $12 \mathrm{~m}$ \\
5 & F & $15 \mathrm{Y}$ & 55 & 5 & T4-S1 & $12 \mathrm{~m}$ \\
6 & M & $17 \mathrm{Y}$ & 63 & 14 & T2-T11 & $24 \mathrm{~m}$ \\
7 & F & $19 \mathrm{Y}$ & 60 & 12 & T3-SI & $18 \mathrm{~m}$ \\
8 & F & $23 \mathrm{Y}$ & 52 & 10 & T4-L3 & $12 \mathrm{~m}$ \\
9 & F & $18 \mathrm{Y}$ & 55 & 5 & T5-L2 & $12 \mathrm{~m}$ \\
10 & F & $18 \mathrm{Y}$ & 53 & 10 & T3-T12 & $18 \mathrm{~m}$ \\
11 & F & $19 \mathrm{Y}$ & 60 & 17 & T5-L3 & $18 \mathrm{~m}$ \\
12 & M & $16 \mathrm{Y}$ & 55 & 13 & T4-L2 & $12 \mathrm{~m}$ \\
\hline
\end{tabular}




\section{Case Presentation}

- Male patient 16 years old, presented with back deformity with cobb's angle 50 degrees (Figure 4).

- Postoperative (Figure 5):

- Cobb's angle 10 without complication.

- The patient's back appearance was improved and the patient was satisfied, but back pain that need medication and physiotherapy was present.

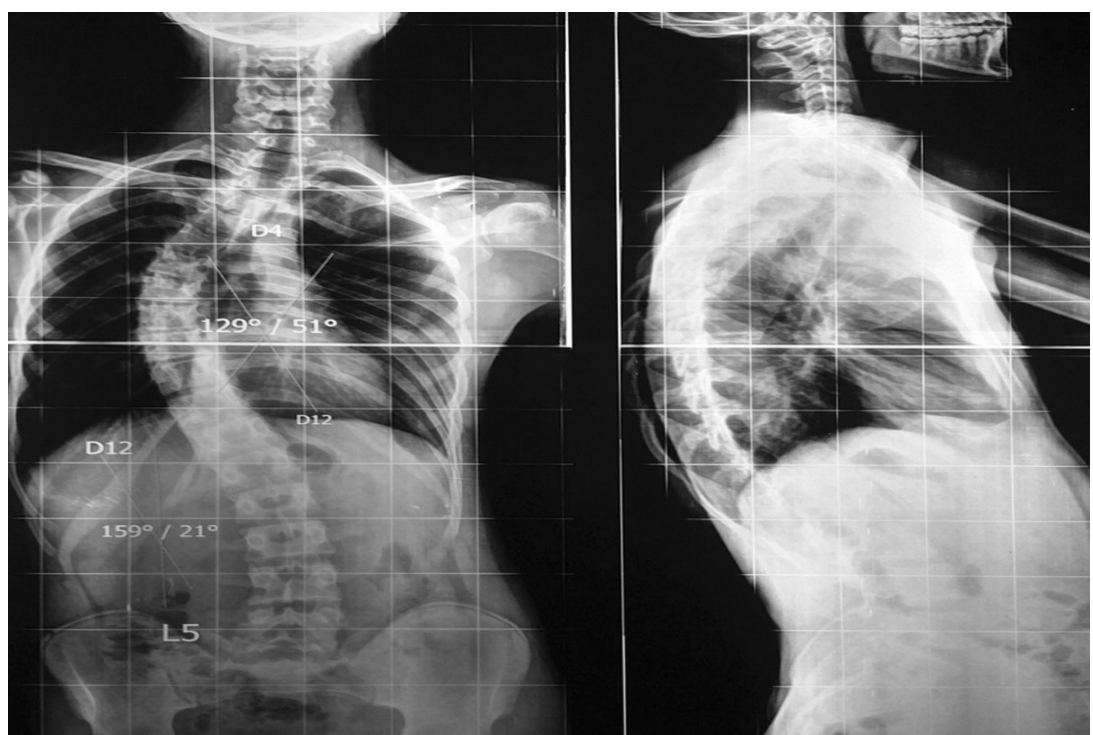

Figure 4. Preoperative plain radiograph.

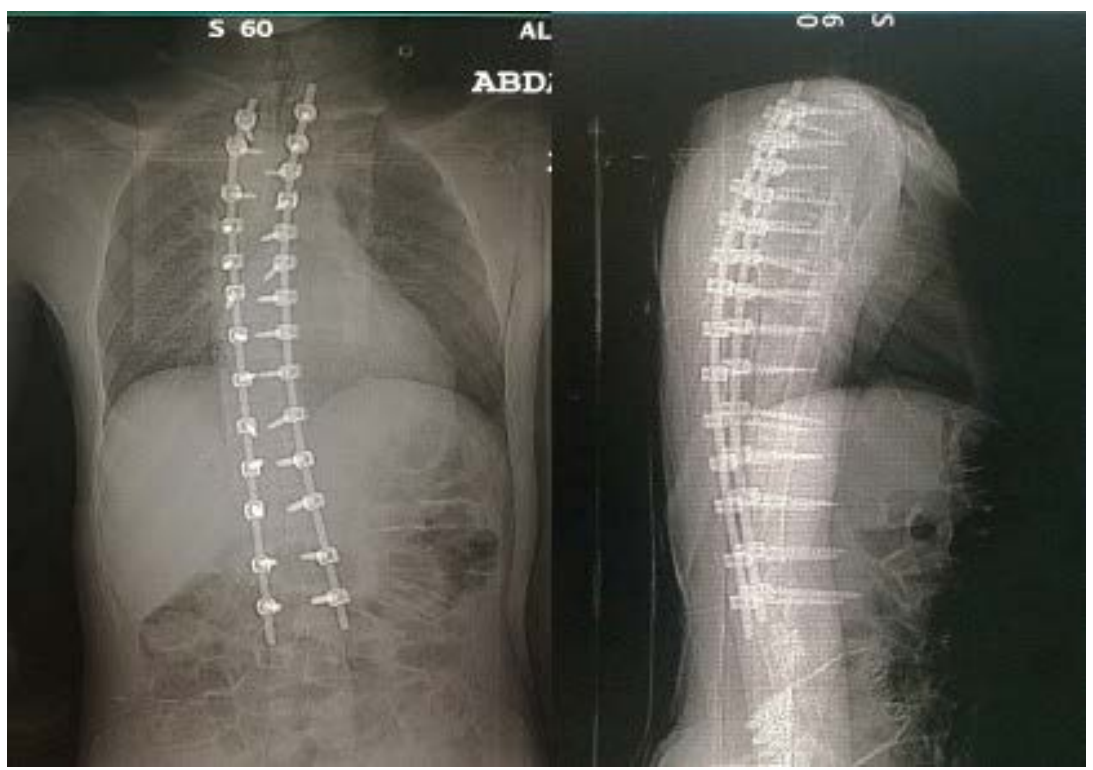

Figure 5. Postoperative plain radiograph.

\section{Discussion}

This study was performed on 12 patients with idiopathic kyphoscoliosis who underwent freehand surgical correction: 9 patients were female, 3 were male. 
Mean age 15 years ranged from $(7-23) .8$ cases with a thoracolumbar curve, 4 cases with the thoracic curve. 9 cases presented with deformity and back pain and 3 cases with deformity alone.

The early outcome showed Cobb's angle and coronal balance improved significantly after surgery $95 \%$ correction in 2 cases $(17 \%), 80 \%$ correction in 8 cases $(66 \%), 60 \%$ correction in 2 cases (17\%) which came in the agreement of Patel et al., 2018 [31], Min et al., 2013 [32], Lenke et al., 2010 [33] and Olgun and Yazici, 2013 [34].

Patel et al., 2018 reported that the mean preoperative Cobb angle was $96.54^{\circ}$, the mean postoperative angle was $30.77^{\circ}$, and the mean angle at final follow-up was $34.81^{\circ}$ (average loss of correction of $4.23^{\circ}$ ), for a final average correction of $64.15 \%$. Concerning scoliosis, the mean preoperative angle was $52.54^{\circ}$, the mean postoperative angle was $15.77^{\circ}$, and the mean angle at final follow-up was $19.42^{\circ}$ (average loss of correction of $3.66^{\circ}$ ), for a final average correction of $60.95 \%$ [31].

Min et al., 2013 reported a $79.1 \%$ correction rate which is higher than most of the previously reported studies using all pedicle screws, which ranged between $62 \%$ and $77 \%$ [32].

Lenke et al., 2010 reported that The severe scoliosis cases had a correction rate of $69 \%, 54 \%$ for the global kyphosis cases, $63 \%$ for the angular kyphosis cases, and 56\% for the combined kyphoscoliosis cases [33].

Olgun and Yazici 2013 reviewed the advantages of anterior versus posterior surgery and concluded that with modern pedicle screws, posterior surgery provides most, if not all, of the advantages of anterior surgery without its negative effect on pulmonary function [34].

Also, the early outcome showed 2 cases have CSF leakage which improved with conservative treatment. 1 case has mal-directed screw into disc space, and 1 case has medial screw into the spinal canal without neurological deficit which came in the agreement of Bakaloudis et al, 2011 [35], Dhurve \& Patil, 2017 [36] and Patel et al., 2018 [31].

Dhurve \& Patil, 2017 reported that the incidence of screw misplacement ranges from $3 \%$ to $44.2 \%$, with screw-related neurologic complications in the $0 \%$ to $0.9 \%$ range. Also reported medial wall violation of the thoracic pedicle between $1.4 \%$ and $14 \%$ from $1 \mathrm{~mm}$ to $8.0 \mathrm{~mm}$, there were no permanent neurologic, cardiovascular, or pulmonary complications associated medial wall violation in many cases [36].

Patel et al., 2018 reported that the overall complication rate was $30.77 \%$. There was a general complication rate of $15 \%$, which included 2 cases of dural tear and 1 case each of implant failure and superficial infection. The neurological complication rate was $7.6 \%$. One patient had a new-onset neurological deficit involving the left L-4 nerve root (quadriceps weakness 3/5), and in 2 other patients, the neurological examination results worsened from preoperative Frankel grade $\mathrm{C}$ to $\mathrm{A}$ in the immediate postoperative period. In these 3 cases, the patients' deficits all had improved with conservative management at the 3-month follow-up [31]. 
Bakaloudis et al. 2011 reported 5 medical complications and 1 neurological complication in their series of 12 patients, for a complication rate of 50\% [35].

Late follow up which is done every 3 months for at least 12 months shows improvement of patient deformity and cosmetic appearance to the degree of patient satisfaction (in 7 cases (58\%) associated with high SRS-30 total scores). However assessment of the pain in comparison to preoperative assessment show improvement of pain in 4 cases (33\%), persistent in 4 cases (33\%), and appear in 4 cases (33\%) which came in the agreement of Cuartas et al., 2009 [37], Dong et al., 2021 [38] and Yilmaz et al., 2012 [39].

Dong et al., 2021 reported that 52 patients were treated with freehand, and a total of 888 screws were placed. The average preoperative Cobb angle of the patients was $52.0^{\circ} \pm 15.7^{\circ}\left(21^{\circ}-103^{\circ}\right)$, and the screw placement satisfaction rate reached $88.5 \%$. No screw-related complications occurred. The overall screw placement in this trial was satisfied [38].

Cuartas et al., 2009 reported that there is also evidence suggestive that the posterior-only surgery with pedicle screw instrumentation for AIS is associated with improved clinical outcomes including improved SRS scores [37].

Yilmaz et al., 2012 reported that The optimal implants for posterior fixation should achieve better curve correction with high safety profile and minimal implant-related complications [39].

\section{Conclusion}

To conclude, freehand one-stage correction for management of idiopathic kyphoscoliosis though the posterior approach is a safe and effective method for near-total correction of spinal deformity with a good functional outcome with minimal complications.

\section{Ethical Approval}

Patients had informed consent.

\section{Authorship}

All the listed authors contributed significantly to the conception and design of study, acquisition, analysis, and interpretation of data and drafting of the manuscript, to justify authorship.

\section{Conflicts of Interest}

The author declares no conflicts of interest regarding the publication of this paper.

\section{References}

[1] Al-Bashir, A.K., Al-Abed, M.A., Amari, H.K., Al-Rousan, F.M., Bashmaf, O.M., Abdulhay, E.W., et al. (2019) Computer-Based Cobb Angle Measurement Using Deflection Points in Adolescence Idiopathic Scoliosis from Radiographic Images. 
Neural Computing and Applications, 31, 1547-1561. https://doi.org/10.1007/s00521-018-3614-y

[2] Slattery, C., Sokol, S. and Verma, K. (2019) Understanding Classification Systems in Spine Deformity. Clinical Spine Surgery, 32, 64-66.

https://doi.org/10.1097/BSD.0000000000000699

[3] Pahys, J.M. and Guille, J.T. (2018) What's New in Congenital Scoliosis? Journal of Pediatric Orthopaedics, 38, e172-e179. https://doi.org/10.1097/BPO.0000000000000922

[4] Bertoncelli, C.M., Bertoncelli, D., Elbaum, L., Latalski, M., Altamura, P., Musoff, C., et al. (2018) Validation of a Clinical Prediction Model for the Development of Neuromuscular Scoliosis: A Multinational Study. Pediatric Neurology, 79, 14-20. https://doi.org/10.1016/j.pediatrneurol.2017.10.019

[5] Hägglund, G., Pettersson, K., Czuba, T., Persson-Bunke, M. and Rodby-Bousquet, E. (2018) Incidence of Scoliosis in Cerebral Palsy: A Population-Based Study of 962 Young Individuals. Acta Orthopaedica, 89, 443-447. https://doi.org/10.1080/17453674.2018.1450091

[6] Li, J., Hu, Z.S., Tseng, C.C., Zhao, Z.H., Yuan, Y.W., Zhu, Z.Z., et al. (2019) Radiographic and Clinical Outcomes of Surgical Correction of Poliomyelitis-Related Spinal Deformities: A Comparison among Three Types of Pelvic Instrumentations. World Neurosurgery, 122, e1111-e1119. https://doi.org/10.1016/j.wneu.2018.10.238

[7] Angelliaume, A., Harper, L., Lalioui, A., Delgove, A. and Lefèvre, Y. (2018) TailorMade Management of Thoracic Scoliosis with Cervical Hyperextension in Muscular Dystrophy. European Spine Journal, 27, 264-269.

https://doi.org/10.1007/s00586-017-5113-8

[8] Machida, M., Weinstein, S.L. and Dubousset, J. (2018) Pathogenesis of Idiopathic Scoliosis. Springer, Tokyo. https://doi.org/10.1007/978-4-431-56541-3

[9] Kelly, J.J., Shah, N.V., Freetly, T.J., Dekis, J.C., Hariri, O.K., Walker, S.E., et al. (2018) Treatment of Adolescent Idiopathic Scoliosis and Evaluation of the Adolescent Patient. Current Orthopaedic Practice, 29, 424-429. https://doi.org/10.1097/BCO.0000000000000675

[10] Barton, C.B. and Weinstein, S.L. (2018) Adolescent Idiopathic Scoliosis: Natural History. In: Machida, M., Weinstein, S. and Dubousset, J., Eds., Pathogenesis of Idiopathic Scoliosis, Springer, Tokyo, 27-50.

https://doi.org/10.1007/978-4-431-56541-3 2

[11] El Hawary, R. and Chukwunyerenwa, C. (2014) Update on Evaluation and Treatment of Scoliosis. Pediatric Clinics of North America, 61, 1223-1241. https://doi.org/10.1016/j.pcl.2014.08.007

[12] Pau, M., Leban, B., Pilloni, G., Porta, M., Cubeddu, F., Secci, C., et al. (2018) Trunk Rotation Alters Postural Sway but Not Gait in Female Children and Early Adolescents: Results from a School-Based Screening for Scoliosis. Gait \& Posture, 61, 301-305. https://doi.org/10.1016/j.gaitpost.2018.01.031

[13] Mundis, G.M., Blakemore, L.C. and Akbarnia, B.A. (2016) Idiopathic Early Onset Scoliosis. In: Akbarnia, B., Yazici, M. and Thompson, G., Eds., The Growing Spine, Springer, Berlin, 151-166. https://doi.org/10.1007/978-3-662-48284-1 10

[14] Dimeglio, A., Canavese, F. and Bonnel, F. (2016) Normal Growth of the Spine and Thorax. In: Akbarnia, B., Yazici, M. and Thompson, G., Eds., The Growing Spine, Springer, Berlin, 47-82. https://doi.org/10.1007/978-3-662-48284-1 4

[15] Faraj, S.S.A., Holewijn, R.M., van Hooff, M.L., de Kleuver, M., Pellisé, F. and Haanstra, T.M. (2016) De Novo Degenerative Lumbar Scoliosis: A Systematic Review of Prognostic Factors for Curve Progression. European Spine Journal, 25, 2347-2358. 
https://doi.org/10.1007/s00586-016-4619-9

[16] Kim, H., Kim, H.S., Moon, E.S., Yoon, C.S., Chung, T.S., Song, H.T., et al. (2010) Scoliosis Imaging: What Radiologists Should Know? RadioGraphics, 30, 1823-1842. https://doi.org/10.1148/rg.307105061

[17] Cruz, D.L. and Protopsaltis, T. (2017) Imaging Adult Lumbar Scoliosis. In: Klineberg, E., Ed., Adult Lumbar Scoliosis, Springer, Cham, 11-21. https://doi.org/10.1007/978-3-319-47709-1_2

[18] Dean, A.J. and Kessler, R. (2017) Plain Chapter. Clinical Emergency Radiology, 55, 12.

[19] Rosa, S., Baird, J.W., Harshfield, D. and Chehrenama, M. (2018) Craniocervical Junction Syndrome: Anatomy of the Craniocervical and Atlantoaxial Junctions and the Effect of Misalignment on Cerebrospinal Fluid Flow. In: Gürer, B., Ed., Hydrocephalus- Water on the Brain, IntechOpen, London. https://doi.org/10.5772/intechopen.72890

[20] Singrakhia, M., Malewar, N. and Jangle, A. (2018) Intraspinal Anomalies in Early Onset Scoliosis: Current Concepts. Journal of Pediatric Neurosciences, 13, 294-301. https://doi.org/10.4103/JPN.JPN 10017

[21] Choudhry, M.N., Ahmad, Z. and Verma, R. (2016) Adolescent Idiopathic Scoliosis. The Open Orthopaedics Journal, 10, 143-154.

[22] Musson, R.E., Warren, D.J., Bickle, I., Connolly, D.J. and Griffiths, P.D. (2010) Imaging in Childhood Scoliosis: A Pictorial Review. Postgraduate Medical Journal, 86, 419-427. https://doi.org/10.1136/pgmj.2009.089128

[23] Gillingham, B.L., Fan, R.A. and Akbarnia, B.A. (2006) Early Onset Idiopathic Scoliosis. JAAOS-Journal of the American Academy of Orthopaedic Surgeons, 14, 101-112. https://doi.org/10.5435/00124635-200602000-00005

[24] Balsano, M. and Negri, S. (2019) Diagnosis and Conservative Treatment of Adolescent Idiopathic Scoliosis: Case Presentation. In: Meyer, B. and Rauschmann, M., Eds., Spine Surgery, Springer, Cham, 149-152. https://doi.org/10.1007/978-3-319-98875-7 20

[25] Karimi, M.T. and Rabczuk, T. (2018) Scoliosis Conservative Treatment: A Review of Literature. Journal of Craniovertebral Junction \& Spine, 9, 3-8.

[26] Ridderbusch, K., Spiro, A.S., Kunkel, P., Grolle, B., Stücker, R. and Rupprecht, M. (2018) Strategies for Treating Scoliosis in Early Childhood. Deutsches Ärzteblatt International, 115, 371-376. https://doi.org/10.3238/arztebl.2018.0371

[27] Davis, L., Murphy, J.S., Shaw, K.A., Cash, K., Devito, D.P. and Schmitz, M.L. (2019) Nighttime Bracing with the Providence Thoracolumbosacral Orthosis for Treatment of Adolescent Idiopathic Scoliosis: A Retrospective Consecutive Clinical Series. Prosthetics and Orthotics International, 43, 158-162. https://doi.org/10.1177/0309364618792727

[28] Aulisa, A.G., et al. (2018) Brace Treatment of Idiopathic Scoliosis Is Effective for a Curve over 40 Degrees, but Is the Evaluation of Cobb Angle the Only Parameter for the Indication of Treatment? European Journal of Physical and Rehabilitation Medicine, 55, 231-240.

[29] Workman, J.K., Wilkes, J., Presson, A.P., Xu, Y., Heflin, J.A. and Smith, J.T. (2018) Variation in Adolescent Idiopathic Scoliosis Surgery: Implications for Improving Healthcare Value. The Journal of Pediatrics, 195, 213-219.

[30] Bettany-Saltikov, J., Weiss, H.R., Chockalingam, N., Taranu, R., Srinivas, S., Hogg, J., et al. (2015) Surgical versus Non-Surgical Interventions in People with Adolescent idiopathic Scoliosis. Cochrane Database of Systematic Reviews. 
https://doi.org/10.1002/14651858.CD010663.pub2

[31] Patel, A., Ruparel, S., Dusad, T., Mehta, G. and Kundnani, V. (2018) PosteriorApproach Single-Level Apical Spinal Osteotomy in Pediatric Patients for Severe Rigid Kyphoscoliosis: Long-Term Clinical and Radiological Outcomes. Journal of Neurosurgery: Pediatrics, 21, 606-614. https://doi.org/10.3171/2017.12.PEDS17404

[32] Min, K., Sdzuy, C. and Farshad, M. (2013) Posterior Correction of Thoracic Adolescent Idiopathic Scoliosis with Pedicle Screw Instrumentation: Results of $48 \mathrm{~Pa}$ tients with Minimal 10-Year Follow-Up. European Spine Journal, 22, 345-354. https://doi.org/10.1007/s00586-012-2533-3

[33] Lenke, L.G., Sides, B.A., Koester, L.A., Hensley, M. and Blanke, K.M. (2010) Vertebral Column Resection for the Treatment of Severe Spinal Deformity. Clinical Orthopaedics and Related Research, 468, 687-699. https://doi.org/10.1007/s11999-009-1037-x

[34] Yazici, M. and Olgun, Z.D. (2013) Growing Rod Concepts: State of the Art. European Spine Journal, 22, 118-130. https://doi.org/10.1007/s00586-012-2327-7

[35] Bakaloudis, G., Lolli, F., Di Silvestre, M., Greggi, T., Astolfi, S., Martikos, K., et al. (2011) Thoracic Pedicle Subtraction Osteotomy in the Treatment of Severe Pediatric Deformities. European Spine Journal, 20, Article No. 95.

https://doi.org/10.1007/s00586-011-1749-y

[36] Dhurve, K. and Patil, V. (2017) Accuracy of Free Hand Technique of Transpedicular Screw Fixation in Correction of Spinal Deformities. International Journal of Orthopaedics Sciences, 3, 701-706. https://doi.org/10.22271/ortho.2017.v3.i3j.108

[37] Cuartas, E., Rasouli, A., O’Brien, M. and Shufflebarger, H.L. (2009) Use of All-Pedicle-Screw Constructs in the Treatment of Adolescent Idiopathic Scoliosis. JAAOS Journal of the American Academy of Orthopaedic Surgeons, 17, 550-561. https://doi.org/10.5435/00124635-200909000-00002

[38] Dong, Q., Huang, Z., Sun, Y., Zeng, Y. and Chen, Z. (2021) Prediction of Accuracy and Screw Size by Pedicle Anatomic Parameters and Screws in Idiopathic Scoliosis With Freehand Screw Placement Based on Machine Learning. Research Square. https://doi.org/10.21203/rs.3.rs-165556/v1

[39] Yilmaz, G., Borkhuu, B., Dhawale, A.A., Oto, M., Littleton, A.G., Mason, D.E., et al. (2012) Comparative Analysis of Hook, Hybrid, and Pedicle Screw Instrumentation in the Posterior Treatment of Adolescent Idiopathic Scoliosis. Journal of Pediatric Orthopaedics, 32, 490-499. https://doi.org/10.1097/BPO.0b013e318250c629 